\title{
Increased metabolic and cardiovascular morbidity in patients with schizophrenia: recommendation for diagnoses and treatment
}

\author{
Dan Cohen
}

\author{
From $1^{\text {st }}$ International Congress on Neurobiology and Clinical Psychopharmacology and European \\ Psychiatric Association Conference on Treatment Guidance \\ Thessaloniki, Greece. 19-22 November 2009
}

Metabolic syndrome, diabetes and other cardiovascular risk factors are highly prevalent in people with schizophrenia. Patients are at risk for premature mortality and overall have limited access to physical health care. In part these cardio-metabolic risk factors are attributable to unhealthy lifestyle, including poor diet, high rates of smoking and sedentary behaviour. But over recent years it has become apparent that antipsychotic agents can have a negative impact on some of the modifiable risk factors. The psychiatrist needs to be aware of the potential metabolic side effects of antipsychotic medication and to include them in the risk/benefit assessment when choosing a specific antipsychotic. He should also be responsible for the implementation of the necessary screening assessments and referral for treatment of any physical illness. Multidisciplinary assessment of psychiatric and medical conditions is needed. The somatic treatments offered to people with severe and enduring mental illness should be at par with general health care in the non-psychiatrically ill population.

The recently published joint recommendations of EPA, EASD and ESC on diabetes and cardiovascular risk in patients with severe mental disorders should be implemented in all mental health services.

Published: 22 April 2010

doi:10.1186/1744-859X-9-S1-S33

Cite this article as: Cohen: Increased metabolic and cardiovascular morbidity in patients with schizophrenia: recommendation for diagnoses and treatment. Annals of General Psychiatry 2010 9(Suppl 1):S33.

Department of Clinical Epidemiology, University of Groningen, Netherlands
Submit your next manuscript to BioMed Central and take full advantage of:

- Convenient online submission

- Thorough peer review

- No space constraints or color figure charges

- Immediate publication on acceptance

- Inclusion in PubMed, CAS, Scopus and Google Scholar

- Research which is freely available for redistribution 